\title{
Impacts of COVID-19 on the Real Estate Market in the Czech Republic
}

\author{
Eduard $\mathrm{H}$ romada ${ }^{1}$, \\ ${ }^{1}$ Czech Technical University in Prague, Faculty of Civil Engineering, Thakurova 7, Prague 6, Czech \\ Republic
}

\begin{abstract}
The article deals with the description of the impacts of COVID19 on the real estate market in the Czech Republic. The article focuses on the housing market - sales and rentals of apartments. The article contains graphs that show the development before COVID-19 and during COVID19. Trends are indicated as the real estate market will develop in the next period. All results published in this article were created using the EVAL software, which the author of the article has been developing since 2007. This software continuously maps real estate advertising within all cities in the Czech Republic.
\end{abstract}

Keywords: real estate market, software, big data, statistics

\section{Introduction}

The presence of COVID-19 affected all areas of human activity, including the real estate market. At the beginning of the pandemic, many experts expected a significant drop in prices in the real estate market. These expectations turned out to be wrong. COVID-19 caused the real estate market to freeze in the months of March to June 2020, but from July 2020 the situation has changed. Currently, the average price level of the real estate market (sales of apartments) is higher than before the start of the pandemic COVID-19. Only the rental housing market in Prague is still affected by the pandemic.

\section{Literature review}

Many authors examine the development of the real estate market. They use various methods and procedures for this, which are further innovated. Various specialized software is used that can collect, analyse and evaluate large data. The problem is the evaluation of results, which due to inappropriate aggregation can provide the public with inaccurate information about trends in the real estate market. For example, a common mistake is to average results for too large a location (such as a state). In a given state, there are usually diverse areas with different socio-economic characteristics and population structure.

These articles describe the development of the real estate market, for example [3], [2], [11]. The authors focus on the market in their home state or home city. The dependences of individual parameters of the real estate market, for example on employment, the extent of

\footnotetext{
* Corresponding author: eduard.hromada@fsv.cvut.cz
} 
mortgages, the age of the population, the balance of migration, the extent of new construction, etc., are examined. The paper [1] studies the housing market in Florida. Paper [9] discusses about the life-cycle cost analysis in relation to building's value assessment. The article [6] examines the dependencies of how immigration affects real estate prices in the locality. It was found that there is a big difference between whether rich immigrants come to the locality or immigrants without sufficient financial background.

Many authors [8], [4], [10], [7] also search for models that evaluate the real estate market. These models are used, for example, for investors to decide on the most advantageous real estate or to manage the risks associated with the acquisition and operation of real estate. These models are usually based on collecting a large set of data using automated algorithms.

Paper [5] elaborates on methods of automated data acquisition based on web mining, reviews methods of econometric spatial modelling with impact of proximity in order to deduct efficiency parameters within different categories.

\section{Methodology of data collection}

The results on the development of the real estate market in the Czech Republic were processed using the software tool EVAL, which the author of this paper is developing at the Faculty of Civil Engineering of the Czech Technical University in Prague. The software systematically collects, analyses and evaluates real estate price offers published on the real estate server www.sreality.cz. Currently, the scope of the software application covers all published advertisements in the category of apartments for sale and apartments for rent from this real estate server. Information is collected regularly over a period of one month, starting in 2007. Due to the situation with COVID-19, the data collection interval was shortened to a period of 15 days, always on the first and fifteenth day of the month.

The software recorded the following number of advertisements for individual cities in 2020 (January to September 2020): Prague (56,460 records), Brno (6,627 records), České Budějovice (1,673 records), Ostrava (4,887 records) and Ústí nad Labem (1,299 records).

The data show the offer prices published in the real estate advertisement. These are not actually realized prices. The results show trends in the development of the real estate market, in the current time. The data set was adjusted for advertisements that contain obviously incorrectly entered data by advertisers, as well as for advertisements for which the price was not filled.

\section{Results}

\subsection{Apartments for sale in large cities in the Czech Republic}

The effects of the measures on the COVID-19 pandemic have not yet had a significant effect on real estate sales prices in the Czech Republic. The real estate market usually reacts with a certain delay. Immediately after the measures were taken due to the pandemic, the real estate market froze. Since June 2020, there has been an increase in turnover on the real estate market and a further rise in prices. At present, real estate prices in Prague and the surrounding area are already higher than they were before the onset of the pandemic.

In the next period, we can expect further growth in sales prices of apartments. This is mainly due to the following factors:

- Central bank policy - quantitative easing. People are afraid of inflation and the devaluation of their savings. This newly printed money is usually not covered by any labour, value or production. Unfortunately, this money is used mainly for immediate 
consumption and is thus fully transferred to inflation (especially to the stock market, real estate, bonds). Many people are already realizing this risk and are trying to protect their capital. This is a key factor that will prevent real estate prices from falling even in the event of a recession.

- Decrease in mortgage interest rates, lack of alternative investment for capital appreciation and failure of pension reform.

- In the next period, developers want to keep part of their production (approximately 20$30 \%$ of the offer of flats they produce) and rent them themselves. Furthermore, they want to sell a large part of their production (up to $20-50 \%$ ) directly as whole apartment buildings to funds and corporations. So the offer of new individual flats available to the general public (natural persons) will be significantly reduced with all the impacts. What is lacking is expensive.

- There is a lack of labour in the construction industry from abroad. There is no one to replace this workforce. Czech workers usually do not want to work in manual professions. If, however, some foreign workers are forced to be replaced by Czech workers, the work will become more expensive and thus the results of their work.

- The effects of the pandemic slowed down ongoing construction and delayed approval processes at building authorities. So new construction output will emerge more slowly.

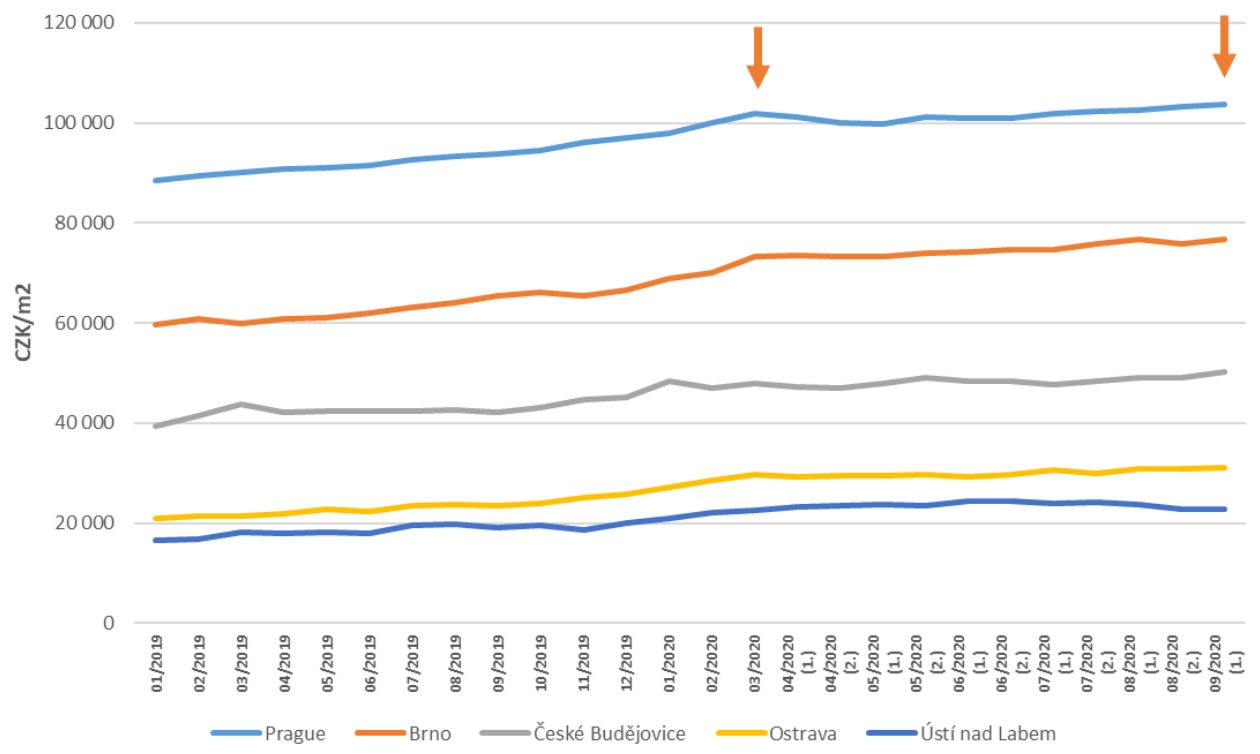

Fig. 1. Development of offer prices of apartments for sale in selected cities of the Czech Republic medians

Source: Own processing.

The number of apartments offered for sale has a long-term downward trend. Only the AirBnB phenomenon in Prague and Brno and limited travel cause a temporary fluctuation in the number of apartments offered for sale upwards. In the medium term, a further decline in the number of apartments offered for sale throughout the Czech Republic can be expected. Construction companies and developers will limit new construction due to expectations of a 
global recession and a reduction in the demand side (lower purchasing power of the population, reduced availability of mortgages relative to household income, lower willingness to borrow, lower willingness to take risks, etc.).

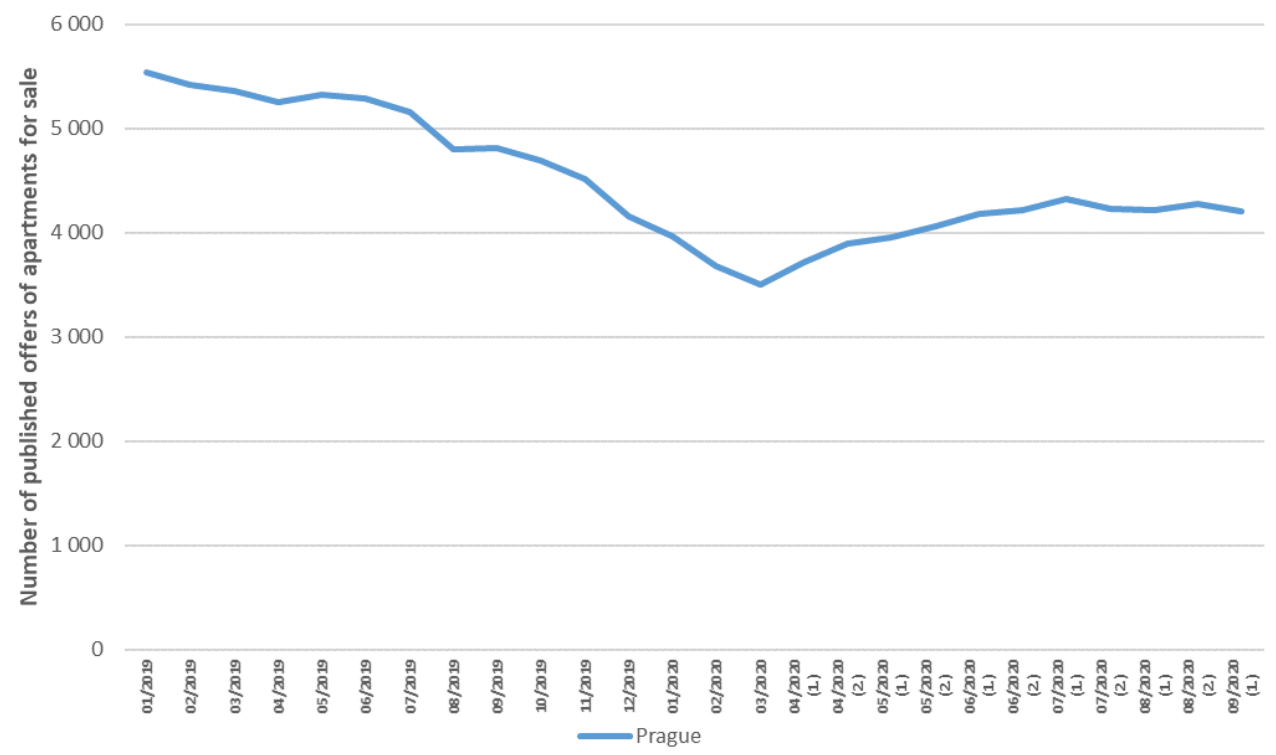

Fig. 2. Development of the number of apartments offered for sale in Prague Source: Own processing.

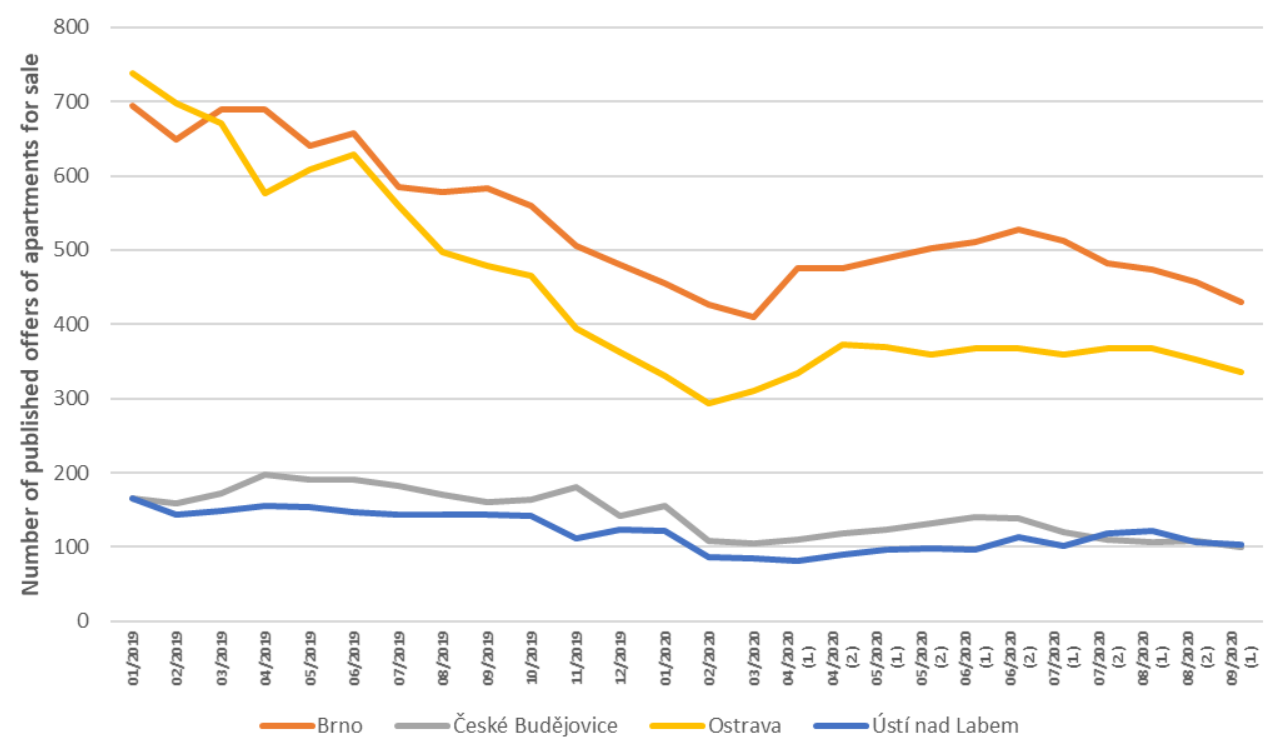

Fig. 3. Development of the number of apartments offered for sale in selected cities of the Czech Republic

Source: Own processing. 


\subsection{Apartments for rent in large cities in the Czech Republic}

The effects of the COVID-19 pandemic were significantly reflected in the price of apartment rentals in Prague. This applies especially to apartments in the centre of Prague. Many AirBnB homeowners have started offering long-term rentals instead of short-term rentals. With this step, the offer of rental flats was expanded and prices fell. There is a paradoxical situation that rental prices in Brno are close to rental prices in Prague, while job opportunities and wages are significantly higher in Prague than in Brno.

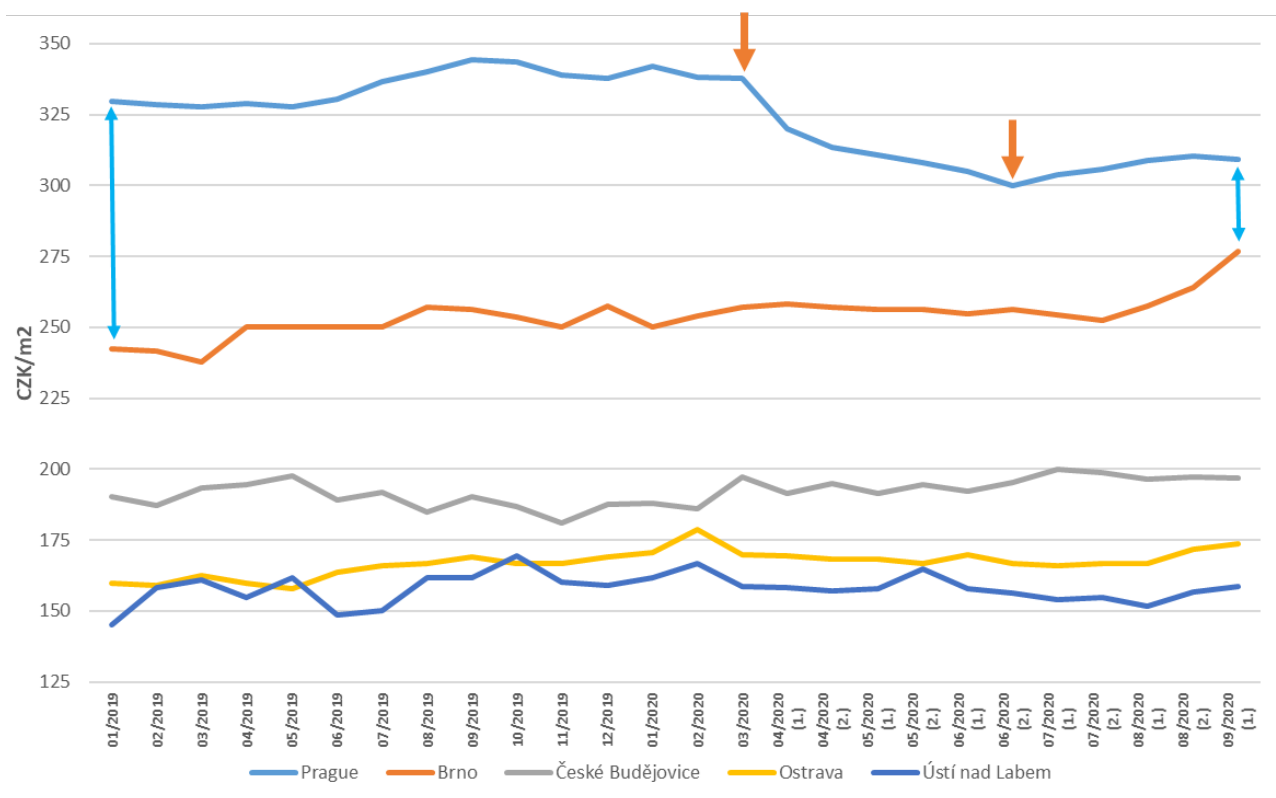

Fig. 4. Development of offer prices of apartments for rent in selected cities of the Czech Republic medians

Source: Own processing.

The impacts of COVID-19 and the related shortfall in income from short-term leases caused a significant increase in the number of flats offered for rent in Prague and Brno. The situation was accelerated by the fact that at one point (suddenly) thousands of flats in Prague were returned to the rental market. The real estate market was not able to absorb this oversupply quickly. In other cities in the Czech Republic (with the exception of Český Krumlov and other attractive tourist destinations for foreign visitors), the impact of the AirBnB phenomenon is negligible.

In terms of the number of published advertisements offering apartments for rent, in April, May and June 2020 there was a massive increase in the number of offers for Prague and Brno apartments. From July 2020, the beginning of a change in the trend in Prague and Brno is evident. In Prague and Brno, the number of advertisements for rent is already declining. Other cities in the Czech Republic, where the AirBnB phenomenon is not significantly present (Ústí nad Labem, Ostrava, Zlín, etc.), maintain a similar development as before COVID-19. In 
addition, the related Figure 5 and 6 show a drop in the number of offers in August, September and October 2019 due to increased demand for rental housing from university students.

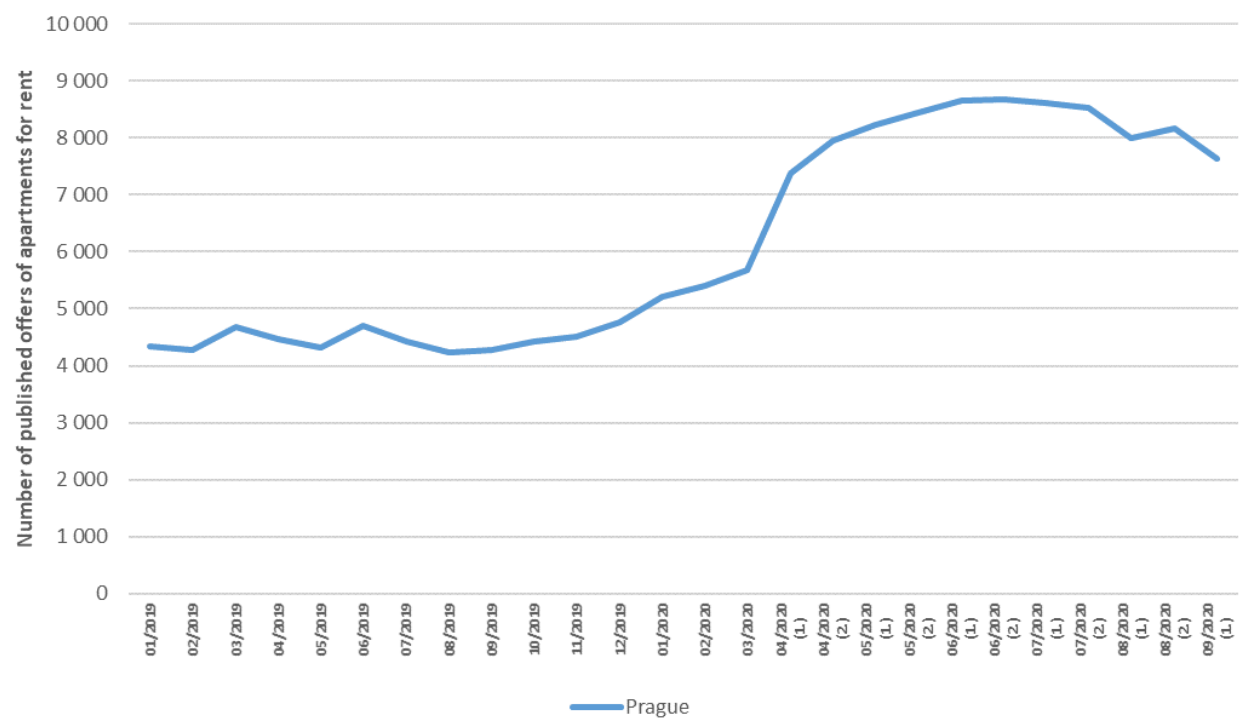

Fig. 5. Development of the number of advertisements for apartments intended for rent in Prague Source: Own processing.

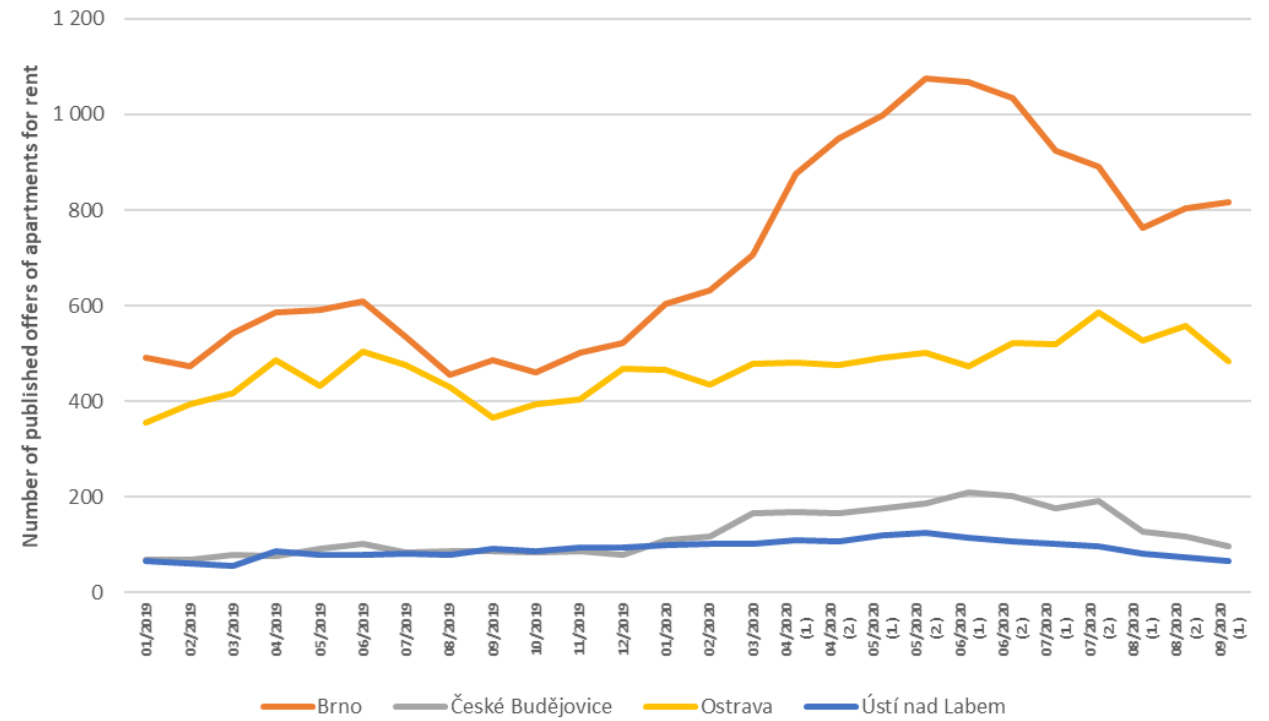

Fig. 6. Development of the number of advertisements for apartments intended for rent in selected cities in the Czech Republic

Source: Own processing. 


\section{Conclusion}

In the next period, a deterioration in the financial affordability of owner-occupied and rented housing can be expected. In the area of apartment sales, AirBnB apartment sales can be expected from financially weaker property owners to stronger market players, including foreign ones. These can be, for example, wealthy individuals and corporate entities. It can be expected that developers will focus primarily on corporate clients in the coming period. The COVID-19 pandemic will accelerate the already started trends in the real estate market, such as accelerating the accumulation of assets towards the richest group of the population and strengthening the rentier capital.

The demand will increase especially for cheap flats and rooms for rent with good public transport access to the centre of Prague. There will be a fluctuation of tenants from more expensive real estate to cheaper real estate. Price will be the deciding factor, not the quality of housing. This trend will affect especially owners of AirBnB apartments in the centre of Prague, who have newly renovated apartments, equipped with quality and expensive furniture, who have invested a large amount of initial capital in the acquisition and reconstruction and cannot afford to rent them at lower prices.

\section{References}

1. A. Temilola, H. Chi, Investigation of Florida Housing Prices Using Predictive Time Series Model. Proceedings of the Practice and Experience on Advanced Research Computing, pp. 1-4 (2018)

2. G. Massimo, The Predictability of Real Estate Excess Returns: An Out-of-Sample Economic Value Analysis. The Journal of Real Estate Finance and Economics, (2020)

3. H. Xin, Search Benefit in Housing Markets: An Inverted U-Shaped Price and TOM Relation: Search Benefit in Housing Markets. Real Estate Economics, 48(3), 772-807 (2020)

4. L. Beatriz, A Computer-Assisted Expert Algorithm for Real Estate Valuation in Spanish Cities. Environment and Planning B: Urban Analytics and City Science, (2020)

5. G. Muggenhuber, Geospatial Data Mining and Analytics for Real-Estate Applications. Service-Oriented Mapping, Springer International Publishing, pp. 225-40 (2019)

6. A. Pavlov, T. Somerville, Immigration, Capital Flows and Housing Prices. Real Estate Economics, 48(3), 915-49 (2020)

7. J. Pike, The Future of Sustainable Real Estate Investments in a Post-COVID-19 World. Journal of European Real Estate Research, (2020)

8. H. Rabiei-Dastjerdi, Gap Analysis in Decision Support Systems for Real-Estate in the Era of the Digital Earth. International Journal of Digital Earth, 1-18 (2020)

9. R. Schneiderova Heralova, Building's value assessment using the utility and the LCC. CESB 2007 Prague International Conference - Central Europe Towards Sustainable Building, (2007)

10. S. R. Kumar, Factors Influencing Dividend Decisions of Indian Construction, Housing and Real Estate Companies: An Empirical Panel Data Analysis. International Journal of Finance \& Economics, (2020)

11. R. Wisniewski, J. Brzezicka, Glocal Real Estate Market: Evidence from European Countries. Journal of European Real Estate Research, (2020) 